\section{The internal representation of information in the form of hierarchies}

\section{DIANA DEUTSCH \\ University of California at San Diego, La Jolla, California}

An issue of considerable interest to perceptual and cognitive psychology concerns the internal representation of information in the form of hierarchies. Strong evidence has accumulated for the encoding of visual scenes as hierarchies of subscenes (Bower \& Glass, 1976; Hanson \& Riseman, 1978; Navon, 1977; Palmer, 1977; Winston, 1973). Sophisticated hierarchical models of the representation of sentence structure have been advanced (Chomsky, 1963; Miller \& Chomsky, 1963; Yngve, 1960). The hierarchical structure of tonal music has been the subject of considerable analysis (Lerdahl \& Jackendoff, 1977; Meyer, 1956, 1973; Narmour, 1977; Salzer, 1962; Schenker, 1956, 1973). It has been shown that, when presented with hierarchically organized serial patterns, subjects' encodings of these patterns reflect pattern structure (Bjork, 1968; Kotovsky \& Simon, 1973; Restle, 1970; Restle \& Brown, 1970; Simon \& Kotovsky, 1963; Simon \& Sumner, 1968; Vitz \& Todd, 1967, 1969).

In considering how hierarchically structured information is internally represented, models utilizing hierarchies of operators have proved particularly useful (Greeno \& Simon, 1974; Restle, 1970). Recently, I, together with the mathematician John Feroe, have proposed a model for the internal representation of pitch sequences in tonal music that utilizes this approach (Deutsch \& Feroe, 1981). This model, which is also briefly described in Deutsch (1980), has recently been seriously misdescribed by Jones (1981). The major purpose of the present note is to dispel any misconceptions about the model that may have arisen as a result of this erroneous description.'

In the model of Deutsch and Feroe (1981), pitch sequences are assumed to be represented as hierarchical networks. At each level of the hierarchy, elements are organized as structural units in accordance with laws of figural goodness such as proximity and good continuation. Elements at each hierarchical level are elaborated by further elements so as to form structural units at the next-lower level, until the lowest level is attained.

At each level of the hierarchy, there exists a set of

Preparation of this paper was supported by U.S. Public Health Service Grant MH-21001. The author is grateful to John Feroe for valuable discussions. The author's complete address is: Center for Human Information Processing, University of California at San Diego, La Jolla, California 92093. structures, each of which is associated with an alphabet. A structure is notated as $\left(A_{1}, A_{2}, \ldots, A_{l-2}\right.$, $\left.A_{\ell-1}, *, A_{l+1}, A_{\ell+2}, \ldots, A_{n}\right)$, where $A_{j}$ is one of the operators $\mathrm{n}, \mathrm{p}, \mathrm{s}, \mathrm{ni}^{\mathrm{i}}, \mathrm{p}$. The symbol ${ }^{*}$ provides a reference point for the other operators, and appears exactly once in a structure. ${ }^{2}$ The combination of a structure and an alphabet is termed a sequence. A sequence, together with a reference element, produces a sequence of notes.

A compound sequence is produced by the combination of two or more sequences under the action of a sequence operator. The central sequence operator is a pr (prime), with two others, ret (retrograde) and inv (inversion) defined as elaborations of pr. The designation of a reference element for a compound sequence produces a sequence of notes. ${ }^{3}$

In her paper, Jones (1981) attacks a nonexistent model, and claims that it is ours. I here draw attention to some of her erroneous statements.

(1) "Deutsch apparently means not a particular rule configuration, but a two-level 'hierarchy of subsequences'" (p. 499). This is unequivocally false, and the reader is referred to Deutsch and Feroe (1981) for several examples of multileveled structures described in terms of the system.

(2) "The critical device that Deutsch introduces to achieve hierarchical structure involves two alphabets" (p. 499). This is unequivocally false. Not only are multiple alphabets involved, but more importantly, the hierarchical organization of the operators does not depend on the associated alphabets.

(3) "II]n an apparent attempt to reflect the special role of the tonic and dominant notes in music, Deutsch allows a subsequence of rules to begin with any note within a chunk" (p. 500, italics added). The statement in italics is unequivocally false and demonstrates not only that Jones has failed to comprehend the abstract structure of the system, but also that she has failed to comprehend the musical issues involved.

There are other places where Jones makes inappropriate objections to our model. For example, she objects to the fact that the reference element is not necessarily the first element of a structure, so that operators to the left of it give rise to notes that occur earlier in time. However, there is nothing mathematically wrong or psychologically implausible about this assumption. Indeed, as described at length in Deutsch and Feroe (1981), this flexibility in placement of the reference element is of importance, and reflects the fact that the dominant element in a sequence is often not the first element of the sequence. Numerous examples in our paper are given to illustrate this point.

Elsewhere, Jones claims that "Deutsch confounds rule configuration with the individual rules used" (p. 500). Again, this is completely false. In Deutsch 
and Feroe (1981), considerable space is devoted to the argument that whereas a large number of alternative representations of a sequence may in principle be constructed on our model, various cognitive constraints greatly reduce the number of alternative representations that the listener will invoke. These include optimal chunk size, and laws of figural goodness such as proximity and good continuation. Numerous examples are given to illustrate this point also.

Perhaps the major objection to the model raised by Jones is that it is not hierarchical by her definition. It is therefore important that her definition be made clear. She writes: "The simplest clue to a hierarchical serial pattern is that the entire second half of the sequence can always be generated ... from the first half by a single rule"' (p. 493).

Now it is certainly the case that the sequences with which our model is concerned do not fall within this narrow classification. Indeed, if they did, the model would have very little explanatory value for tonal music, in which sequences falling within this classification very rarely occur. The same argument applies to hierarchical models of sentence structure, of visual scene recognition, and so on. Thus, if we were to take Jones's definition seriously, most published work on the internal representation of information in the form of hierarchies would have to be discarded. It should also be noted that, from a mathematical standpoint, there is no justification for Jones's insistence on this narrow definition.

Jones's lack of understanding of our model and her insistence on this narrow definition of "hierarchy" has caused her to argue that certain controls should have been performed in the study by Deutsch (1981) which are, in fact, quite inappropriate. For example, she proposes a control experiment comparing sequences which are hierarchical by her definition with those that are not. While she should feel free to pursue such an experiment for her own interest, it is inappropriate as a control in the context of our model. Other thought experiments that she suggests are unrelated to the model-for example, an experiment investigating how the effect of temporal segmentation would behave when the relative durations of pauses to pattern segments were varied.

Finally, I should draw attention to Jones's statement that "Greeno and Simon (1974) and Jones (1974) discovered the application of group theoretic principles to serial patterns"' (p. 495). In fact, this approach, which was pioneered by Babbitt (1960, 1961), had been in the mainstream of music theory for over a decade; and the article by Babbitt (1961) was referenced by Greeno and Simon (1974) in this context.

\section{REFERENCES}

BABвitт, M. Twelve-tone invariants as compositional determinants. The Musical Quarterly, 1960, 46, 246-259.
BАввітт, M. Set structure as a compositional determinant. Journal of Music Theory, 1961, 5, 72-94.

BJork, R. A. All-or-none subprocesses in the learning of complex sequences. Journal of Mathematical Psychology, 1968, 5, 182-195.

Bower, G. H., \& Glass, A. L. Structural units and the redintegrative power of picture fragments. Journal of Experimental Psychology: Human Learning and Memory, 1976, 2, 456-466.

Chомsкy, N. Formal properties of grammars. In R. D. Luce, R. R. Bush, \& E. Galanter (Eds.), Handbook of mathematical psychology (Vol. 2). New York: Wiley, 1963.

DEUTSCH, D. The processing of structured and unstructured tonal sequences. Perception \& Psychophysics, 1980, 28, 381-389.

Deutsch, D., \& FERoe, J. The internal representation of pitch sequences in tonal music. Psychological Review, 1981, 88, $503-522$.

Greeno, J. G., \& Simon, H. A. Processes for sequence production. Psychological Review, 1974, 81, 187-196.

Hanson, A. R., \& Riseman, E. M. (Eds.) Computer vision systems. New York: Academic Press, 1978.

Jones, M. R. Cognitive representations of serial patterns. In B. Kantowitz (Ed.), Human information processing: Tutorials in performance and cognition. Potomac, Md: Erlbaum, 1974.

Jones, M. R. A tutorial on some issues and methods in serial pattern research. Perception \& Psychophysics, 1981, 30, 492-504.

Kotovsky, K., \& Simon, H. A. Empirical tests of a theory of human acquisition of concepts of sequential events. Cognitive Psychology, 1973, 4, 399-424.

LERDAHL, F., \& JACKENDOFF, R. Toward a formal theory of music. Journal of Music Theory, 1977, 21, 111-172.

MEYER, L. B. Emotion and meaning in music. Chicago: University of Chicago Press, 1956.

MEYER, L. B. Explaining music: Essays and explorations. Berkeley: University of California Press, 1973.

Mille R, G. A., \& Chomsky, N. Finitary models of language users. In R. D. Luce, R. R. Bush, \& E. Galanter (Eds.), Handbook of mathematical psychology (Vol. 2). New York: Wiley, 1963.

Narmour, E. Beyond Schenkerism. Chicago: University of Chicago Press, 1977.

Navon, D. Forest before trees: The precedence of global features in visual perception. Cognitive Psychology, 1977, 9, 353-383.

Palmer, S. E. Hierarchical structure in perceptual representation. Cognitive Psychology, 1977, 9, 441-474.

RestLe, F. Theory of serial pattern learning: Structural trees. Psychological Review, 1970, 77, 481-495.

Restle, F., \& Brown, E. Organization of serial pattern learning. In G. Bower (Ed.), The psychology of learning and motivation: Advances in research and theory (Vol. 4). New York: Academic Press, 1970.

SALzE R, F. Structural hearing. New York: Dover, 1962.

Schenker, H. Neue musikalische Theorien und Phantasien: Der freie Satz. Vienna: Universal Edition, 1956.

SCHENKER, H. In O. Jonas (Ed. and annotator; E. M. Borgese, trans.), Harmony. Cambridge, Mass: M.I.T. Press, 1973.

Simon, H. A., \& Kotovsky, K. Human acquisition of concepts for sequential patterns. Psychological Review, 1963, 70, 534-546.

Simon, H. A., \& Sumner, R. K. Pattern in music. In B. Kleinmuntz (Ed.), Formal representation of human judgment. New York: Wiley, 1968.

VITz, P. C., \& TodD, T. C. A model of learning for simple repeating binary patterns. Journal of Experimental Psychology, $1967,75,108-117$.

Vitz, P. C., \& Tond, T. C. A coded element model of the perceptual processing of sequential stimuli. Psychological Review, $1969,76,433-449$.

Winston, P. H. Learning to identify toy block structures. In R. L. Solso (Ed.), Contemporary issues in cognitive psychology: The Loyola Symposium. Washington, D.C: Winston, 1973.

YNGVE, V. H. A model and an hypothesis for language structure. Proceedings of the American Philosophical Society, 1960, 104, 444-466. 


\section{NOTES}

1. The Deutsch and Feroe (1981) article was referenced by Deutsch (1980) and was available at the time that the Jones (1981) article was written.

2. The symbols $s$ (same), $n$ (next), $p$ (predecessor), $n^{i}$, and $p$ are from Simon (1972).
3. This description of the model is necessarily brief, and the reader is referred to Deutsch and Feroe (1981) for a full description.
(Manuscript received February 1, 1982; accepted for publication February 10, 1982.) 